Journal of Qualitative Criminal Justice \& Criminology

\title{
From Burlesque to Grand Theft Auto: A Historical Analysis of the Treatment of the Media-Crime Relationship in Criminology Texts
}

Lisa A. Kort-Butler ${ }^{\mathbf{1}}$, Michael Killingsworth ${ }^{\mathbf{1}}$

${ }^{1}$ University of Nebraska-Lincoln

Published on: Apr 01, 2014

DOl: $10.21428 / 88 d e 04 a 1.4008 b f e 6$

License: Creative Commons Attribution 4.0 International License (CC-BY 4.0). 


\section{ABSTRACT}

The degree to which criminological scholarship on the media-crime relationship has been subject to the tides of moral panics is not well-understood, although there are theoretical reasons to hypothesize about the role of scientists in moral panics. Textbooks are one location in which a discipline chronicles its scholarly history and speaks to the public, making texts an important site for understanding how scholars interpret the media-crime relationship. A content analysis of over 200 criminology texts, ranging in publication dates from 1880 to 2012, was conducted. Almost half the texts covered the media-crime relationship. These texts often appeared to be responding to and concurring with public debates brought on by moral panics. Textbooks most frequently took a negative stance on the media-crime relationship, as opposed to a more neutral stance or balanced approach. Proportionally, the media-crime relationship received the most coverage in the 1950s, 1990s, and 2000 s, decades that correspond to surges of public debates about comics and video games. The decision of many authors to take a negative position in texts, while others cited contrary evidence, may reflect scholarly authors' participation, intentionally or not, in the panic process.

\section{Introduction}

Burlesque, insensate, spiritless and undiscriminating, demoralizes both the audience and the players. It debases the public taste.-Heyward (1885, p. 477)

If there is ever something to get fired up about, or if you ever wondered why we're raising a morally tone-dead generation of citizens, take a look at the recently released video game Grand Theft Auto 5. - Ingram (2013)

In the United States, public discussion and policy debates regarding the relationship between the media and crime tend to suffer from generational forgetting; as time passes, discussions about earlier forms of media are given less attention or are dismissed as less relevant. However, concerns about the impact of the media on criminal behavior, deviance, or juvenile delinquency stretch back to the late 1800 s or earlier. In the public and in politics, such concerns have been reflected in claims that link media consumption and deviance, and in reactionary exploratory hearings to inform policy making. The media industry has often capitulated to public fears and political gamesmanship by creating voluntary ratings systems, despite U.S. Supreme Court rulings defending various forms of media as protected speech, such as Joseph Burstyn, Inc. v. Wilson (1952) and Brown v. Entertainment Merchants Association (2011). 1

For its part, the American criminological enterprise, in its research and theorizing, has sporadically engaged in these debates. On the one hand, the historical and cultural literature focus on moral entrepreneurs or moral panics emerging around certain forms of media or groups of media 
consumers, but say less about empirical findings (e.g., Hajdu, 2008; Springhall, 1998). On the other hand, the published empirical research tends to focus on contemporary media types and generally fails to comment on the socio-historical connections binding purported media effects (e.g., Coyne, 2007; Huesmann, 2007; for exceptions, see Miller, 2009; Shipley \& Cavender, 2001). As a result, where the criminological enterprise writ large stands on these issues over time is not well-known; neither is the degree to which the enterprise is influenced by public and political concerns. Recent theorizing about the moral panic process considers the role of scholars in this process (Ferguson, 2008), but little to no research has explored this idea.

The current study was designed to address this lack of information with a content analysis of over 200 criminology textbooks designed for use in academic settings, ranging in publication dates from circa 1880 to 2012. First, we briefly outline the moral panic process, then illustrate how scholars have historically become entwined in moral panics about the media-crime relationship. We also discuss the role of scientific inquiry in the moral panic process based on insights from Ferguson's (2008) moral panic wheel and Downs's (1972) issue attention cycle. Next, we discuss the results of the content analysis, emphasizing context and content while employing an historical-comparative perspective.

\section{Literature Review}

\section{Panic in the public}

History appears to repeat itself in moral panics and the related moral crusades against whatever new media form is believed to spur crime, delinquency, or immoral behavior (Cohen, 1997; Cohen, 2002). For a moral panic to bloom, some sort of latent fear or concern must exist among the general public or certain segments of the population; after all, fear cannot be generated from nothing (Goode \& BenYehuda, 1994). The latent concern in many cases seems to be either the well-being of innocent youth who may be corrupted into lives of crime or the dangerous youth poised for antisocial actions (Faucher, 2008; Springhall, 1998). Although many moral panics do not result in specific institutional changes, they nonetheless leave an informal legacy of consensus-building and norm-reaffirmation (Goode \& Ben-Yehuda, 1994). This legacy and the social processes behind it lay the groundwork for each new round of concern, whether or not advocates of Fear B remember or recount the arguments formulated around Fear A. Cohen (1972) observed that the folk devils around which panics are centered tend to fade from collective memory if the purported calamity tied to them fails to emerge. Newer versions of the evils can thus fill the gap (Ferguson, 2010).

Ironically, the media itself contributes to moral panics about the media-crime relationship. Two factors are implicated: problem-framing and the issue attention cycle (Schildkraut \& Muschert, 2014; Shih, Wijaya, \& Brossard, 2008). First, Altheide (1997) argued that the media, and television in particular, act as a primer by providing information that consumers can use to interpret events. In this process, the media inform the audience that some situation is undesirable, many people are affected 
by it, and the main contributing factors are identifiable. Further, the media employ editorials or commentaries from purported experts, which suggest that the problem can be changed, mechanisms exist to change it, and we as a society already have an agent and process in place to fix the problem. This discourse or problem frame becomes a resource that the audience can use to interpret later information.

Second, the waxing and waning of public issues in the media has been attributed to the issue attention cycle (Downs, 1972). Initially, a problem may not be on the public's radar. However, a phase of alarmed discovery is created when the public becomes suddenly aware of the problem due to a series of reported events. The media play a key role making the public aware of relatively rare situations and contribute to constructing those situations as deeply troubling and widespread (Kappeler \& Potter, 2005; Sacco, 1995). Alarm is followed by apparent widespread public enthusiasm for solving the problem. Once the public realizes the large amount of resources that are necessary to make significant progress in solving the problem, they begin to rethink the situation, enthusiasm wanes, and there is a gradual decline of intense public interest in the issue. Correspondingly, the media often fail to follow up on stories. Consequently, the initial "danger" is revealed, but it is not resolved by continuing coverage (Kappeler \& Potter, 2005). The issue attention cycle concludes in the post-problem stage, in which the public's original concern is now in limbo and a new issue emerges to take its place.

Problem framing surrounding crime issues produces and reproduces public fears and the broader perception that society is dangerous (Altheide, 1997). The latent fear can be used by those interested in a particular issue to advocate for the issue. The problems that reach the issue attention cycle do so because those with the power to define social issues have identified them as such (Schildkraut \& Muschert, 2014). Whether attention fades because the dire forecasts do not materialize or because meaningful solutions are not forthcoming, the issue is never fully resolved. The latent fears are never fully addressed, but the framework needed to regenerate the process remains in place for the next version of the issue.

During the twentieth century, the alignment of problem framing and the issue attention cycle surrounding the media-crime relationship was revealed in the patterning of attention to various forms of media. Utilizing the media, moral entrepreneurs were often successful in persuading the public and the government about the potential damaging effects of the latest media form on young people (see Critcher, 2008 for an historical review). In the United States, concerns over media's suggestive influence spawned congressional investigations, such as the 1954 Senate Subcommittee on Juvenile Delinquency hearings on comic books (i.e., the Kefauver Committee) and the 1985 Senate Commerce Committee hearings on labeling records for explicit lyrics. The Kefauver Committee's (United States Senate, 1954) hearings were televised, providing national exposure for the testimonials of crusaders and sympathetic researchers, exposés of the materials, and interrogations of comic book industry 
executives (Hadju, 2008). The national stage given the hearings solidified a connection between media and deviance in the minds of the public and the polity, however vague that association was. By the 1980s and 1990s, the purported effects of media on children had become "political orthodoxy" (Critcher, 2008, p. 91).

In fact, the model used for assailing comic books was repeated in the Commerce Committee hearings (United States Senate, 1985). Televised hearings featured the proponents of record labeling (the Parents Music Resource Center, an organization led by wives of prominent politicians, including Tipper Gore and Susan Baker), a cast of musicians under fire, and visual and audio aids. However, the advent of cable news agencies and "soft news" programming may now be shifting the stage, such that debates like those seen during televised hearings are played out among commentators and interview guests, including political and public figures (Britto \& Dabney, 2010, p. 200).

Ultimately during the twentieth century, concerns about media's effect on youth created social and political pressure on the American media industry to create numerous, generally voluntary, censorship guidelines and ratings systems, the patterning of which reveals the cyclical nature of old fears dissipating and new ones taking their place. The earliest of these was the Motion Picture Production Code of moral censorship guidelines, instituted in 1930, shortly after the advent of talkies (filmratings.com, n.d.). In 1954, the Comics Code Authority, which censored and approved comics for publication, was established (Hadju, 2008). By 1968, the motion picture industry abandoned censorship for the modern voluntary rating system (filmratings.com, n.d.). The music industry adopted parental advisory labels for explicit lyrics in 1985. The 1990s saw the advent of the Entertainment Software Rating Board ratings for video games in 1994 (esrb.com, n.d.) and the TV Parental Guidance System in 1997 (tvguidelines.org, n.d.). To coordinate with the TV rating system, the V-chip has been included in every TV manufactured since 2000, and modern cable and satellite TV equipment offers parental controls. New devils thus replaced the old, yet the groundwork laid by previous panics set the stage for later efforts to curb immoral behaviors by attempting to control media content (Springhall, 1998).

\section{Panic in the ivory tower}

Like panics in the public, history also appears to repeat itself in scholarship centered on the mediacrime relationship. Even when scholars acknowledge research on earlier forms of media such as TV and movies (Media Violence Commission, 2012), they frequently fail to consider the social history of the media-crime link. For more than 100 years, scholars interested in crime and delinquency have made claims about how the media, writ large, may affect individual behavior (Gunter, 2008). At the turn of the twentieth century, some scholars were concerned that the publication of news stories and photographs about crime would incite imitation among would-be criminals and delinquents, especially the "mentally and morally weak" (MacDonald, 1892, p. 272). Yet, other scholars advocated a more 
tempered approach, arguing that the "suggestive influence" of the sensational press and popular media (e.g., stage and moving pictures) was over-exaggerated (Parmelee, 1918). Art, argued Parmelee (1918), including artistic works, literature, and drama, "is in the main a reflection of conditions which have been created by other forces. It furnishes a picture of those conditions to a certain extent, but is not in itself a strong dynamic force" (p. 118).

During the post-World War II era, psychiatrist Fredric Wertham's research appeared to demonstrate a dangerous link between comics and deviance among youth. His crusade against comic books propelled him to celebrity status among public interest groups and politicians, and he was a star witness during the Kefauver Committee's hearings (e.g., Hajdu, 2008). Among other dissenting academics' voices, Frederic Thrasher of the Chicago school of sociology took a stand on the purported relationship between reading comic books and deviance. Thrasher refuted such a relationship based on lack of empirical evidence and argued that attention to such a relationship amounted to scapegoating.

There is a large broadside of criticism from parents who resent the comics in one way or another or whose adult tastes are offended by comics stories and the ways in which they are presented. These are the same types of parents who were once offended by the dime novel, and later by the movies and the radio. Each of these scapegoats for parental and community failures to educate and socialize children has in turn given way to another as reformers have had their interest diverted to new fields in the face of facts that could not be gainsaid. (Thrasher, 1949, p. 200)

Nearly 65 years later, scholars are divided, sometimes contentiously, over the relationship between playing what are thought to be violent video games and engaging in violent behavior (Critcher, 2008). Research is inconsistent but remains open to a seeming wide degree of interpretation. Researchers appear to refute and doubt the findings of one another, sometimes based less on empirical evidence and more on ideological orientations (Anderson, 2013; Ferguson, 2013). In some outlets, these debates are presented in a more balanced fashion than in the past (Carey, 2013). However, some scholars remain antagonistic, scorning those with whom they disagree. For example, Strasburger, Donnerstein, and Bushman (2014) likened academics who cast doubt on a media-crime relationship to Holocaust deniers.

As these examples over time suggest, the scholarly debate over media's influence tends to mirror the public debates of their respective eras. Despite the scholarly voices in a given era that advocate a narrower interpretation of the data and restraint in public claims-making, other scholars, equally convicted, advocate public action. Two additional examples, one from the comic book debates and one from the video game debates, illustrate how scholars can become integrated into the larger moral panic processes surrounding the media-crime issue. 
First, consider C. Wright Mills' (1954) take on Wertham's (1954) treatise against comic books, Seduction of the Innocent. In a book review for the new York Times, Mills indicated that the issue did not lie with comic strips found in newspapers (which a few decades before were seen as problematic [Hadju, 2008]), but with the "recent upsurge" of violence, crime, and sex in comic books, an upsurge of which parents were ostensibly unaware. Mills extolled Wertham's work and concluded that it did not seem to him that more research was needed before action was taken against publishers. Nonetheless he advocated for additional research, which he thought would undoubtedly bolster Wertham's claim.

Next, consider the arguments Brown and Bobkowski (2012) offered for the shift from research on the TV-aggression link to the video game-aggression link. They argued, first, that users' involvement with video games is more interactive than it was in earlier (electronic) media. Second, video game and computer use is increasingly popular with younger people. Third, perpetrators of school shootings purportedly had histories of playing violent video games. $\stackrel{2}{-}$ Thus, they advocated for additional study of the link between video game playing and violence.

Neither Mills (1954) nor Brown and Bobkowski (2012) were attempting to mislead their audiences. Following purported crime upsurges or extreme events like school shootings, the discourse in the scientific community can change relatively quickly (Ferguson \& Ivory, 2012). The mediums addressed by Mills and by Brown and Bobkowski were viewed in their respective eras as a new, more fearful phenomenon that, anecdotally, had horrible consequences that past mediums could not have had or did not have. Because such scholars believe, based on their interpretation of the research, that an earlier form of media is linked to aggression, they then contend that a new, more virulent medium must also lead to aggression (Critcher, 2008). As such, research into the newer mediums is deemed imperative. These examples reflect acquiescence or acceptance on the part of some scholars to the terms of the moral panic surrounding comic books and video games.

\section{Scholars and the moral panic}

Discussions about moral panics tend to center on out-of-proportion reactions to an issue and the question of who benefits from stirring those reactions (Garland, 2008); typically, the answer to that question is found in power and profit. However, moral judgments on the part of scholars are embedded in what they come to call a moral panic and what they consider to be an appropriate expression of concern (Garland, 2008). The ethics of attribution may also cause scholarly restraint in labeling something a moral panic. Scholars, even if the empirical evidence suggests panic, may refrain from using the term regarding events associated with widespread grief or fear. Garland's (2008) point is that scholars bring their own moral standards to the table when judging a phenomenon's panicworthiness and are unlikely to be wholly objective in their analysis of it. 
Ferguson's $(2008,2010)$ moral panic wheel, modified from the work of Gauntlett (1995), offers additional theoretical insight to the cyclical nature of moral panics as they relate to scientific inquiry, paralleling the issue attention cycle. Based on previous permutations of moral panic theory, Ferguson proposed that societal beliefs about a particular phenomenon, whether those beliefs are cultural, religious, political, or activist in origin, spur media reports on the potential negative effects of the phenomenon. The alarm and enthusiasm in both societal beliefs and media reports about the problem lead to calls for research that verifies and addresses this concern.

According to the moral panic wheel, scholars may become part of the moral panic by producing research that supports the original fear but failing to publish null findings or suppressing research critical of the feared phenomenon (Ferguson \& Kilburn, 2009). In turn, the media report the confirmatory research, which validates sensationalized stories. Politicians pay attention to scholarly work that confirms their positions (Grimes \& Bergen, 2008), and they and other authority figures promote that work for political gain. Scholars may also gain by perpetuating the existing dogma, potentially securing both public legitimacy and funding for their continued research on the topic. The moral panic wheel is completed as the media alight on the ideological and politicized positions regarding the potential negative effects of the feared phenomenon, and then call on experts in the field for their reports. Furthermore, the very use of the term "moral panic" has become a convenient way for news outlets to structure public debates, because the term provides a contrary view that is predictable (Altheide, 2009). Indeed, the term is so convenient that moral advocates, scholars among them, anticipate its use by opponents and provide arguments for why their issue is a "worthwhile" moral panic (Altheide, 2009, p. 91).

However, the issue attention cycle predicts that the fury cannot be maintained. As the public loses interest, these experts and their work become less relevant. The public and the media inevitably move on to something else. Scholars must do likewise to remain relevant, even if the initial target of their inquiry remains empirically unresolved. As one example, the American Psychological Association (APA) issued policy statements in 1985 and 1994 emphasizing the issue of violence in television and film. In 2005 (and currently under review), the APA issued a policy resolution on video games and interactive media that briefly mentioned television, reframed research about television and film, and then cited those studies alongside research about video games to fit the emerging narrative.

Like the public, scholarly attention wanes and issues fade from memory. Taken together, the moral panic wheel and the issue attention cycle suggest that in the drive for social relevance and perhaps for monetary support for their research, scholars may be roused to follow the latest trend in media research and abandon seemingly outdated modalities. Yet the orthodoxy of the media-crime relationship established in Wertham's era remains (Critcher, 2008), as do the empirical and moral judgments of scholars in the field (Garland, 2008). Ferguson and Kilburn (2009) observed "that media 
violence effects research may continue to be driven primarily by ideological or political beliefs rather than objectivity" (p. 762). Scientists, willing or unwittingly, may contribute to the cycle of moral panics about crime and the latest form of media.

\section{The current study}

As Thrasher (1949) forecasted, the newest evil captures the imagination of the public and the ivory tower. Despite the historic record, research may fail to give much attention to the outcomes of panics of past mediums, reflecting the sort of generational forgetting that may occur among the public after moral panics. Perspectives offered by the moral panic wheel and the issue attention cycle provide a framework to understand the place of scholars in this process. However, little research has explored the degree to which scholarship on the media-crime relationship has been (and is) subject to the tides of moral panics.

One approach to detecting changes in scholarly attention to various issues is the standard review of the research literature. Typically, literature reviews are designed to explore the state of research and outline directions for future research. For example, Felson (1996) summarized the literature on television viewing and violent behavior, and Savage (2004) furthered this work with a methodological review of the research. Both of these studies revealed much about the state of research, but neither took a social-historical view in order to account for other forms of media, making it difficult to assess the influence of moral panics. Similarly, meta-analyses can be used to determine the impact of certain variables over time but are affected by selection and publication biases (Wells, 2009), which themselves may reflect the moral panic cycle.

Jensen (2001) offered a different approach, albeit indirectly. Jensen observed that in Edwin Sutherland's influential criminology book, which has seen multiple editions, Sutherland repeatedly addressed the role of television in the learning of crime and delinquency. (For the record, Sutherland [1947] largely discounted such a relationship.) This suggests that criminology textbooks may be a repository of knowledge about trends in scholarly thinking about the media-crime relationship. Textbooks represent the core of knowledge in a discipline, synthesizing theory, research, and even ideology (Keith \& Ender, 2004; Wright, 2000). Textbooks can also play a pivotal role in students' overall learning process and socialization into the discipline. They provide a picture of crime and justice based in empirical reality and represent what the field deems to be important issues (Burns \& Katovich, 2006; Rhineberger, 2006; Sciarabba \& Eterno, 2008; Withrow, Weible, \& Bonnett, 2004). At the same time, textbooks may fail to address fully the historical contexts of criminal justice or neglect certain topics or subareas in a discipline (Huffman \& Overton, 2012; Sciarabba \& Eterno, 2008; Turner, Giacopassi, \& Vandiver, 2006; van der Hoven, 2001). 
The proliferation of research on textbooks reflects the notion that textbooks represent an integral part of how a field defines itself (Keith \& Ender, 2004), making them an important site for research into a discipline. To that end, the current study utilized textbooks to explore how scholarly attention to the media-crime relationship may be integrated into the processes of moral panics. If textbooks (and their authors) are speaking for the discipline, then the content they include and the context in which they present that content hypothetically represent the state of research, and perhaps ideology, regarding a given topic. If there is academic acquiescence to the terms of a moral panic surrounding media, then textbooks may be crafted in such a way to follow that trend, focusing on the newest media forms and either overlooking or reframing older forms.

\section{Methodology}

The sample consisted of criminology and juvenile delinquency textbooks available in the main library at the University of Nebraska-Lincoln, as well as a smaller set of textbooks available in the library of the Department of Sociology at the university. The sample was substantially larger than other criminology or criminal justice textbook studies (e.g., Burns \& Katovich, 2006; Huffman \& Overton, 2012; Sciarabba \& Eterno, 2008; Turner et al., 2006). Nonetheless, the sample was one of convenience, the limitations of which are discussed below.

Because books in the late nineteenth and the early twentieth century do not look like textbooks today, a book was considered a textbook if its intention appeared to be an overview of the field, rather than promoting a particular theory or point of view (Turner et al., 2006). In the libraries, every book from the sections housing criminology and delinquency textbooks was examined and coded if it met selection requirements. Recognizing that editions did not substantially change from one edition to the next, volumes with more than one edition were chosen in an every other year or every odd-numbered edition manner. In total, 223 texts were included in the sample, representing nearly 170 primary authors. $-\frac{3}{-}$ These books were mostly designed for an American audience, but that was not a criterion for inclusion. All were written in or translated into English.

The analysis combined traditional techniques of content analysis with the ethnographic approach advocated by Altheide (1987). Traditional content analyses tend to be quantitative in nature, coding and counting occurrences of pre-designated elements (Maxfield \& Babbie, 1995). This approach, while useful, can result in removing content from context (Muzzatti, 2006). In ethnographically-oriented content analysis, the procedures for data collection, analysis, and interpretation are designed to be reflexive (Altheide, 1987). Theoretically derived categories guide initial stages of a study, but other categories are expected and allowed to arise during the research process. This method is particularly useful when examining texts or contexts over time, because it allows the researcher to remain responsive to historical variations. 
A preliminary coding rubric was constructed based on the research interests and the authors' reviews of several texts. In particular, we were interested in whether textbooks across the decades included mention of the media and a potential causal relationship with deviance, and if so, what genres of media were implicated in what types of deviant behavior. Initial coding was conducted by both researchers and compared to ensure inter-rater reliability. As part of this process, the researchers were responsive to the sample and made appropriate modifications to the coding rubric. Some codes were preset (i.e., number of pages), whereas others remained open-ended. All textbooks in the sample were first coded by their publication date (year) and their coverage of the media-crime relationship (present/not present). For those textbooks in which coverage was present, coding focused on the context and the content of the coverage. That is, in order to gain an overall understanding of how the media-crime relationship was treated in the textbooks, it was important to discover not only whether it was mentioned and in what era, but also where and how it was positioned in the text, what content was discussed, and how the discussion was presented.

Coding categories focused on the context in which the relationship was presented. First, the location of the content was coded as in-text, in a sidebar, or both. Second, the amount of space devoted to the topic was recorded in number of pages. Third, to determine whether the content was presented in a way that was clearly grounded in research, the presence of cited empirical research either in-text or in footnotes was recorded. If present, the publication years of the research were also noted. Fourth, the presence of real-world examples and the nature of the examples (e.g., headline news, notorious names) were recorded. Similarly, whether images were used and their mode of display (i.e., black and white or color; staged or news image) was coded.

Coding categories also focused on the content presented about the media-crime topic. Codes focused on the types of media discussed and the text's treatment of the media-crime relationship, including the effects (i.e., dependent variables) referenced and the overall connotation of the section. First, the codes for categories of the media mentioned by the text included television, radio, movies, books, magazines, comics, video games, music, newspapers, advertisements, dime novels, computer/internet, pictures, theatres, and mass media (general). $\stackrel{4}{ }$ Second, the codes for effects referenced were initially open-ended, then categorized at the end of the coding. These categories included deviance (general), crime (general), aggression, violence (general), violent crime, property crime, white collar crime, juvenile delinquency, drug use/abuse, false reality, desensitization, mental health, sexual offenses, positive effects (e.g., catharsis), effects on policing practices, and effects on anti-social affairs. Finally, the overall connotation of a reference was coded into one of four categories: media has no impact on crime or it has a positive impact (i.e., media reduced crime); $\underline{\underline{5}}$ a negative impact (i.e., media increased crime); a net neutral impact (i.e., the negative, positive, or minimal effects of media on crime balance out); or as presenting both sides without further comment. Texts 
could be coded as representing more than one position, if, for example, media effects were covered in two different sections of a text.

Using this rubric, the sample of textbooks was coded, proceeding as follows. First, the subject index was examined for keywords such as mass media, communications, television, and video games. If any of these words were present, the corresponding sections in the text were coded. Second, the chapter headings and subheadings in the table of contents were examined, and the sections with media content were coded. Third, to make sure nothing was overlooked, each section of the textbook was scanned to see if there was anything about media present. This process allowed for the most comprehensive coverage. The sections containing discussions of media were read several times, then coded for individual elements. The connotation codes were based on the reader's assessment of the overall theme presented in the section. The codes were compiled in a spreadsheet format.

For the purposes of the current study, there were three stages of analysis. In the first stage, we examined the historical trends in exclusion or inclusion of a discussion of the media-crime relationship. In the second stage, we narrowed the analysis to only those texts that addressed the media-crime relationship, taking an historical-comparative approach in order to paint a picture of how scholars chronicled the effects of mass media on crime. In the third stage, we focused on the three decades during which coverage of the media-crime relationship peaked, leading to an analysis of the role of scholars in the moral panic process.

\section{Results and discussion}

\section{The media-crime relationship through textbook history}

Overall, about $43 \%$ of the sample ( 95 textbooks) made reference to media of some sort. Half of the books published from 1880-1926 contained a reference to media ( 3 of 6 texts); none of those published in the 1930s and 1940s did so (0 of 8 texts). The lack of interest in the 1930s and 1940s may be attributed to the large scale social issues occurring during that era, as well as to the limited availability of or access to certain media sources by many in the population. Beginning in the post-World War II era, the textbook industry expanded substantially (Elliot \& Woodward, 1990), so that the sample from that point forward contains more texts. In the 1950 s, $61.5 \%$ of texts contained a discussion of media effects ( 8 of 13 texts), but in the 1960s only $39 \%$ of texts did so (14 of 36 texts). This slow decline continued through the 1970 s and 1980 s, in which $36 \%$ of texts ( 24 of 66 ) and $20.6 \%$ of texts (7 of 34 ), respectively, contained a reference to media. The lack of attention in the 1980 s may be due to a decline of overall interest in media effects or to the absence of any new forms of media during this period. However, this trend reversed in the 1990s, when two-thirds of texts (15 of 23 texts) discussed media. From 2000 to 2009 , nearly $76 \%$ of texts (22 of 29) discussed the media-crime relationship. Of the eight books evaluated for 2010-2012, only one-quarter referenced media but without the full decade, it is difficult to draw conclusions. 


\section{Context: Presenting the media-crime relationship}

The ethnographic approach to content analysis takes into consideration the context in which information was presented. Of the 95 texts that presented information on the media-crime relationship, $90.5 \%$ (86) of the textbooks presented the relationship in the text itself. About $6 \%$ of textbooks also covered the media-crime relationship both in the text and in a side box, and $3 \%$ of the books only covered the relationship in a side box. The average page space devoted to the media-crime relationship across all decades was 3.86 pages. However, there were several outliers, in which books devoted considerable space (8-17 pages) to the topic. Removing those outliers, the average was about 3 pages. By decade, in the 1950s, texts devoted 2.56 pages; in the 1960s, 2.72 pages; in the 1970s, 3.88 pages; in the 1980s, 1.82 pages; in the 1990s, 3.14 pages; and in the 2000s, 2.46 pages. Thus, there appeared to be consistency over time in the type and amount of space devoted to the topic.

One way in which texts may tap directly into moral panics is by using ripped-from-the-headlines examples to discuss media effects. However, few textbooks referencing the media-crime relationship presented real-world examples. Of the 95 texts that mentioned the media-crime relationship, 18 mentioned real-world examples. These examples range from well-known criminal names like Al Capone, to music such as Eric Clapton's I Shot the Sheriff, to school shooting events. There was no clear trend in terms of the nature of these examples, but they were most common in the 2000 s (about $25 \%$ of texts), followed by the 1960s (about $20 \%$ of texts). Images were also infrequently used, which may in part reflect trends in publishing styles. Only 1 book in each decade from the 1960 s to the 1980s used an image. In the 1990s, 2 books used black and white pictures, one was a still of a TV show and one of a person playing video games. Images were most present and the most sensational during the 2000s when about $25 \%$ of books used an image. Of these, 2 showed a color image of a child playing a firstperson shooter video game, 1 showed a black and white image of a person watching TV, and the remaining images depicted criminal justice scenes in black and white (e.g., a police officer talking to a person). Taken together, it appears that the use of examples and images was most common in more recent publications; however, the majority of books from the recent publications did not stage their discussion using these contextual tools.

The intent of coding if research was cited and what research was cited in-text or by footnote was to determine whether the content was presented in a way that was clearly grounded in research. However, the use of citations did not appear until the 1950s, when $75 \%$ of the books provided in-text or footnoted citations. Of books published in the 1960s, $71 \%$ used citations, but in the 1970 s, only $42 \%$ did so. In 1980 s, only $29 \%$ of texts referred to research in-text or in footnotes, and in the 1990 s, $53 \%$ did. By the 2000 s, $73 \%$ of books directly referred to research. These proportions also indicate that many books did not use these citation techniques, making it difficult for the reader to know either the historical record or the relevance of the research. 
For each text, the mean years of distance between citation and publication date was calculated. Those means were used to calculate a mean for the entire sample and by decade. The goal was to determine if cited research encompassed a wide historical range. Citing recent research may present the newest information, but it also means that older research regarding other mediums is overlooked. This may feed into the impression that the current medium is the most problematic or that the issue is entirely new. On the other hand, citing older research may put the current debate in context in order to discuss the issue, but it may also be utilized to demonstrate a purportedly long-standing problem without noting the cultural ebbs and flows. Overall, on average, the cited research across all books from all decades was 11.38 years older than when the textbook was published, but there was not much variation by decade. However, it is worth noting that the range was broad. For the sample, the minimum difference between cited research and publication date was zero and the maximum was about 33 years. There were no clear patterns by decade, but the broad range suggests that authors were intentional about the research they cited. Within-decade variations are discussed in greater detail in the next sections.

\section{Content: Chronicles of the media-crime the relationship}

The next stage of the analysis focused specifically on the content of the media-crime relationship presented in the 95 texts, including the types of media referenced, the effects (dependent variables) considered, the connotation of the coverage, and how each of these changed over time, using decade as the unit of analysis. To examine what types of media gained attention and when, Figure 1 depicts the types of media textbooks cited by decade. Books and newspapers were the first on the scene, followed by movies. Books fell off the radar, but newspapers appeared in every decade. ${ }^{6}$ Movies also had a consistent presence over time. Television, radio, comics, and magazines appeared in the 1950s, and music and the term "mass media" appeared in the 1960s. ${ }^{7}$ By the 1980 s, references to books, magazines, and comics all but disappeared, to be replaced by video games in the 1990s and computers in the 2000s. Importantly, the patterns depicted in Figure 1 illustrate generational forgetting, as certain types of media disappear and are effectively replaced by newer concerns.

Figure 1. Types of media cited across time 


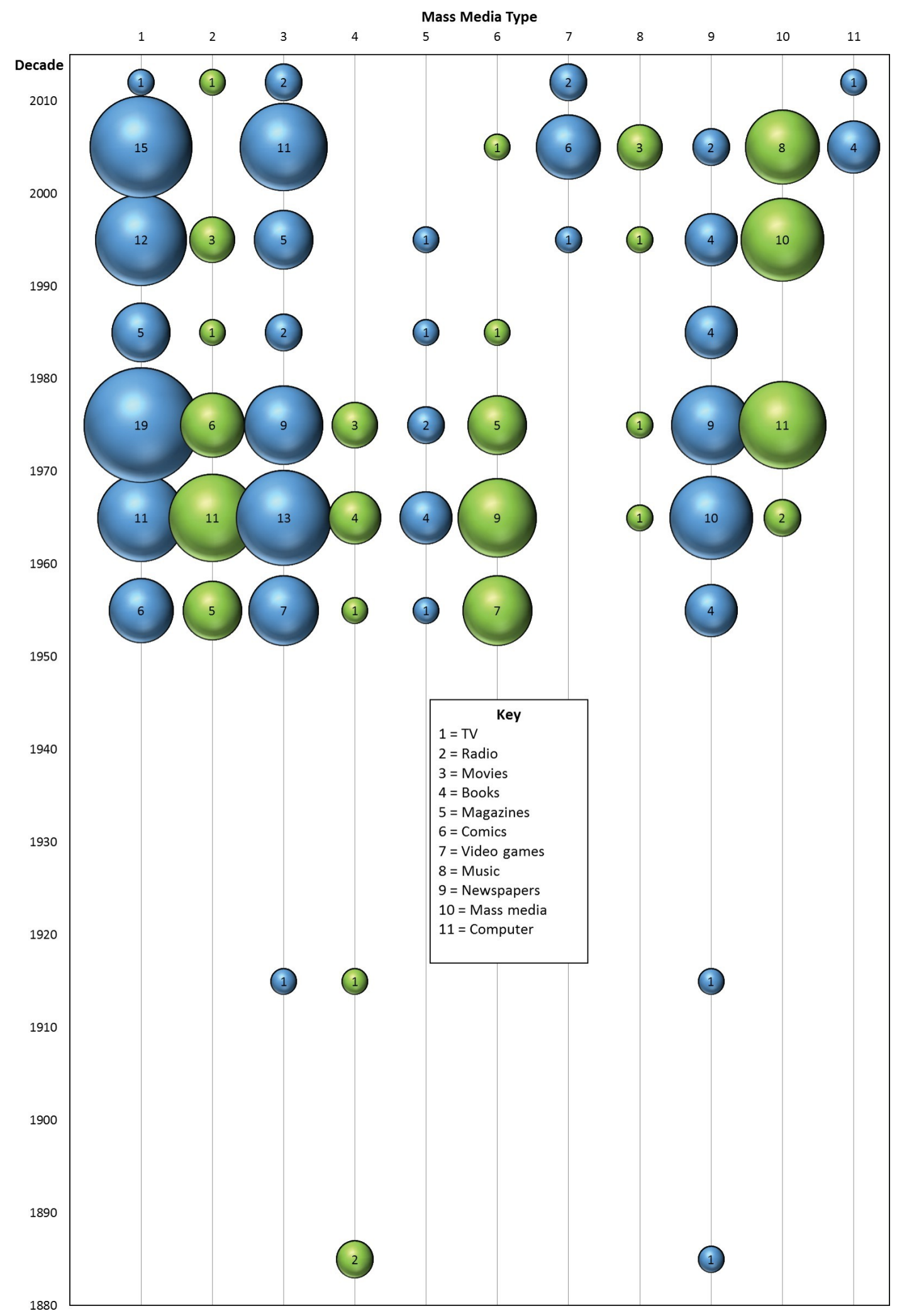

Note: Bubbles represent number of texts per decade that referenced the media type. 
Overall, television and movies appeared to be the most dominant concerns, as did the mass media, once the term was introduced. Indeed, starting in the 1970s, television was the most frequently cited single type of media. By this decade, over $90 \%$ of American households owned a television, and cable television subscription was expanding, reaching $50 \%$ of households in the mid-1980s (tvhistory.tv, n.d.). The other shifts of note-comics and video games/computers-also reflected social trends, namely the moral panics surrounding those mediums, which emerged in the late 1940s and the early to mid-1990s, respectively. The resurgence of interest in the mass media that occurred in the 1990s may also be reflective of the high point in the United States' violent crime rate, the corresponding scare about juvenile violence, and, as Thrasher (1949) might put it, the search for scapegoats.

The purported effects of media on behavior are fuel for moral entrepreneurs, and the textbooks reflected these concerns. The concerns about media's effects on social behavior focused heavily on its purported effects on violence. Violence, aggression, and violent crime were mentioned 58 times. Deviance, generally speaking, was referenced 44 times, and crime was mentioned 17 times. Examining specific crime categories, neither property nor white collar crimes were considered to be concerns, and drug abuse was specifically mentioned only once. In contrast, sexual offenses were named 19 times. The purported effects of media on juvenile delinquency were cited 14 times. Cognitive and emotional effects were also concerns, with 9 references to desensitization to violence, 7 to the role of the media in creating a false perception of reality, 3 to specific positive effects like catharsis, and 2 to mental health concerns.

Figure 2. Effects of mass media referenced over time 


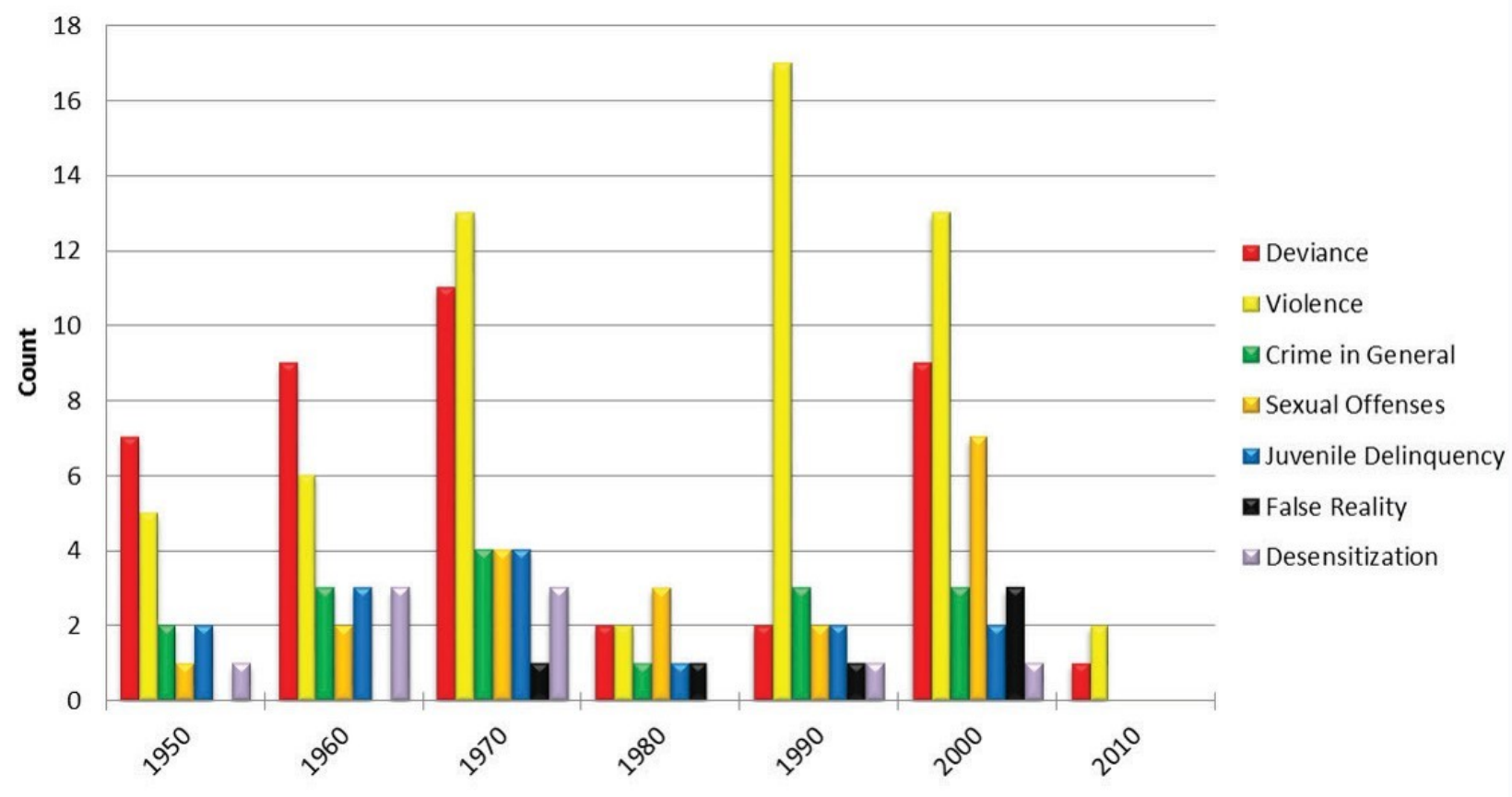

Note: 1880-1940 excluded for ease of presentation.

If shifts in attention to certain types of media are tied to social trends, shifts in concerns about the purported effects of media on behavior should similarly reflect these trends. Figure 2 depicts how these concerns changed over time. For ease of presentation, the earliest decades and the less frequent concerns were excluded from the figure, and the 3 violence categories were combined. Of note, the earliest mentions (1880s, 1900s, 1910s) of the purported effects of media focused on deviance. In the 1950s and 1960s, deviance was the most frequently cited concern followed by violence. In the 1970s, concerns about violence surpassed deviance. After the general lack of attention in the 1980s, there was renewed attention to the purported effects of media on violence in the 1990s, likely reflecting the increases in the violent crime rate, and the public debate about its causes and how to address it. In the 2000s, the effects of media on violence remained a concern, but mentions of deviance and sexual offenses also increased in frequency.

Figure 3. Connotation of media-crime coverage 


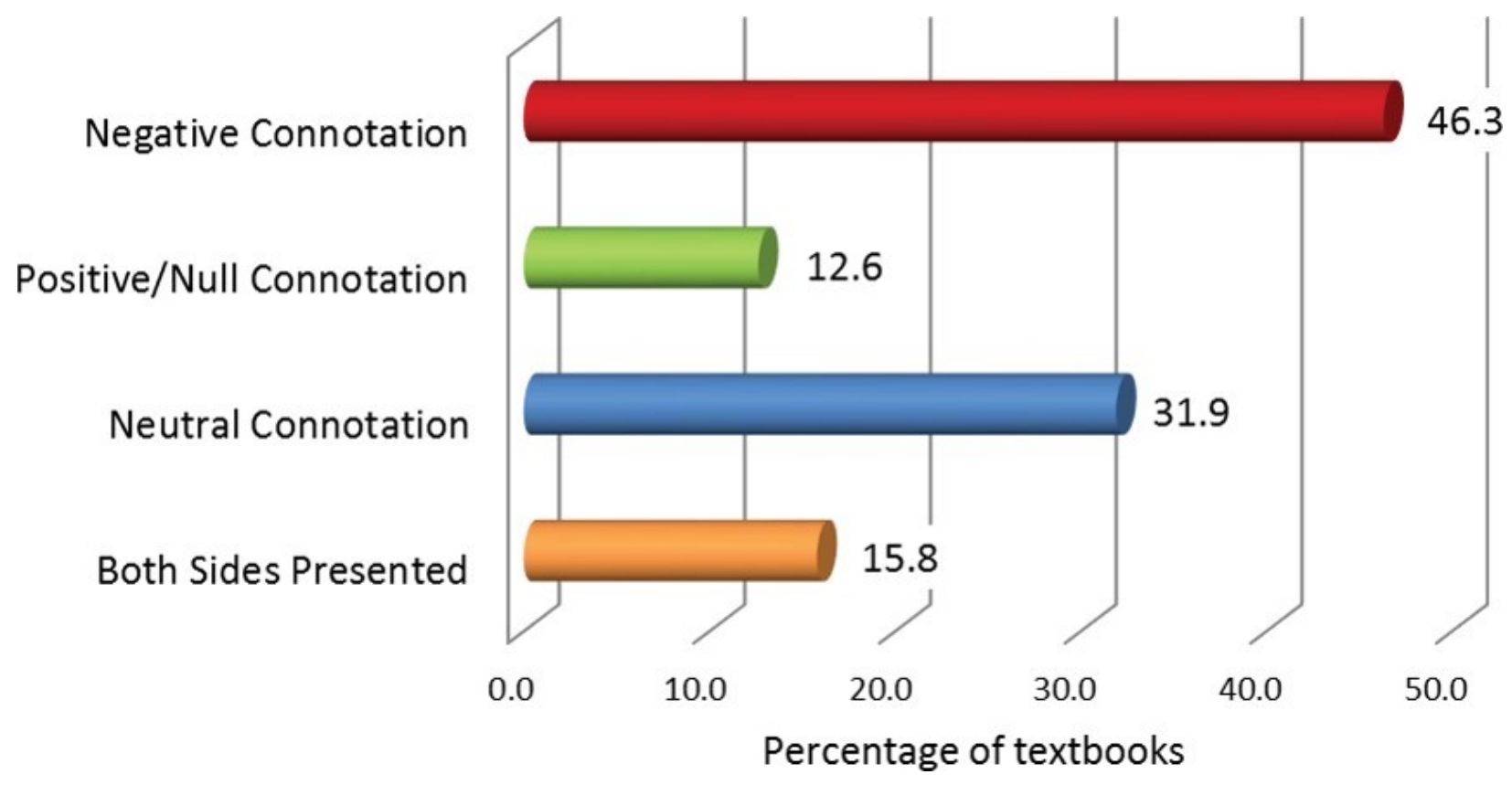

As an initial assessment of the role of texts in supporting (or countering) moral panic, the analysis considered what connotations were present, and if they shifted over time with the types of media covered and their effects. Figure 3 illustrates that the connotation of coverage of the media-crime relationship in the texts tended toward the negative. $-\underline{8}$ Nearly half of the texts made the case that media has a negative impact on behavior, whereas only $12.6 \%$ reported a null or positive effect. About $32 \%$ of texts suggested that the net effect of media on crime was neutral. Approximately $16 \%$ presented both sides of the issue without taking a clear position.

Figure 4. Connotation of media-crime coverage 


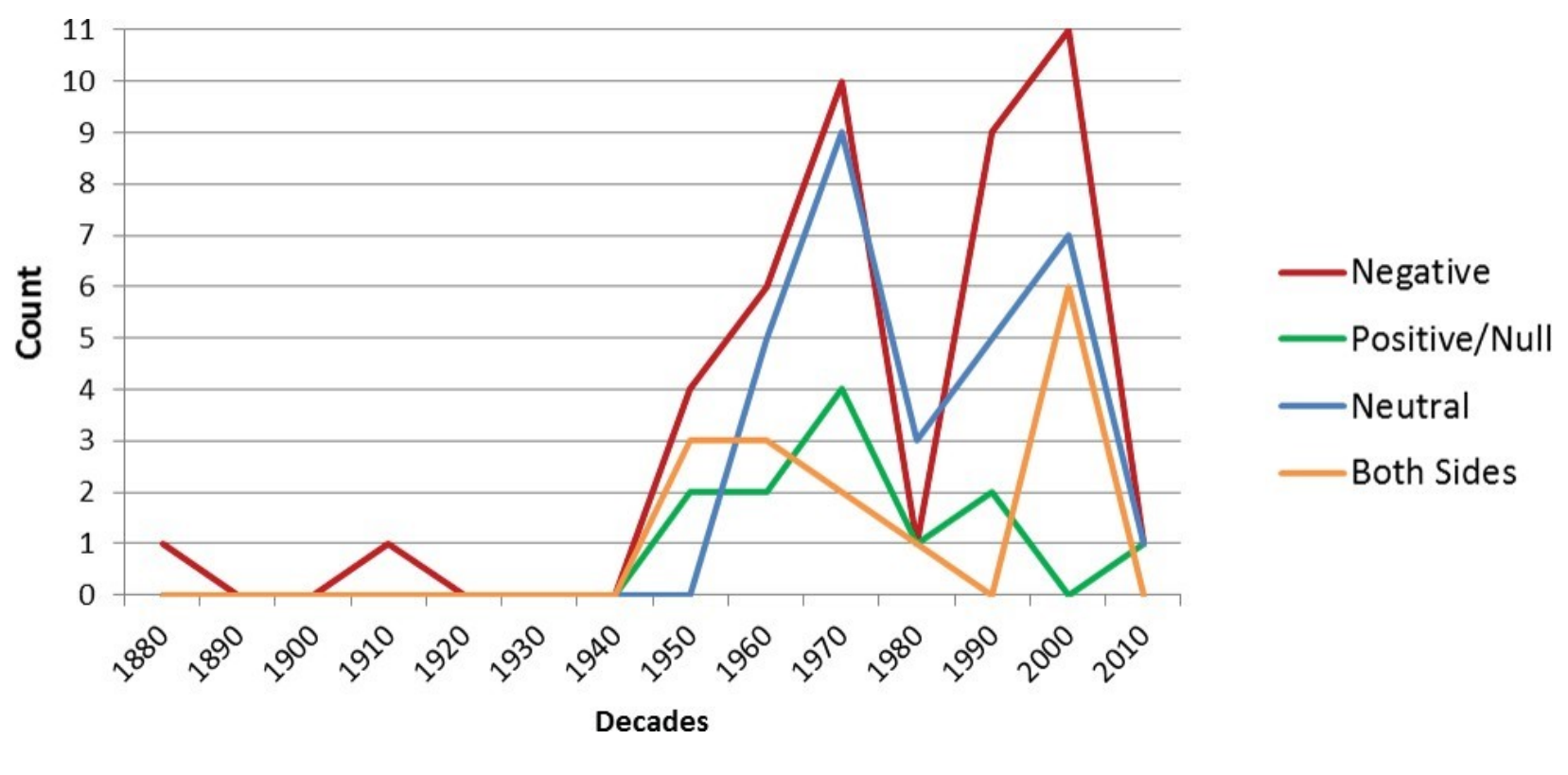

The trends over time are depicted in Figure 4. The negative position was most predominant in every decade except the 1980s. Compared to the other connotations, the inclusion of negative connotations increased through the 1950s and 1960s. By the 1970s, the frequency of neutral connotations nearly matched the negative connotations, and among the few texts in the 1980s, neutral coverage was the most frequent. The 1990s and 2000s saw a rebound in the number of texts reporting an overall negative effect of media. In the 1990s, no text took a neutral stance but some did consider both sides of the issue. By the 2000s, the frequency of both these positions increased, but did not approach the number of texts reporting an overall negative effect of media on behavior. The lack of balance in the most recent decades may reflect the increased public, policy, and scholarly concerns with violence in particular, rather than the more generalized concerns of earlier decades.

\section{The peak decades}

Criminology and delinquency textbooks published in the 1950s, 1990s, and the 2000s saw the highest levels of interest (proportionally) in the media-crime relationship. These eras are associated with two different brands of moral panic, comics in the 1950s and video games and computers in the 1990s and 2000s. These panics resulted in voluntary ratings systems: the Comics Code Authority in the 1950s, and the ESRB video game rating system in the 1990s. In terms of the crime landscape of the eras, there were distinct patterns in homicide rates. Official homicide rates were stable in the 1950 s and began to climb slowly in the 1960s, whereas the 1990s experienced an historical high point in crime rates and a sharp decline that continued into 2000s (Cooper \& Smith, 2011). Textbooks thus gave consideration to the media-crime linkages that came to form the basis for panics in these decades.

How does textbook coverage from these decades compare? Reflecting the moral panics that arose in their respective eras, there were differences in the types of media most frequently referenced. In the 
1950s, comics, movies, television, radio, and newspapers (in that order) were most frequently referenced. By the 1990s, television and mass media received twice the citations as movies, music/radio, or newspapers, and video games make their first appearance in the textbooks. In the 2000s, television still tops the list, then movies, video games and computers, and mass media. There are also differences in the purported effects they considered. In the 1950s, when the crime rate was stable but when post-war concerns about supposedly wayward youth drew public interest, general deviance was the main concern, followed by attention to violence. In contrast, when violent crime was at its peak in the 1990s, violence nearly stood alone. Despite declining rates of violent crime, violence was still the most frequently cited concern in the 2000 s.

The connotations presented in each decade also varied. It appears that at least some texts in each era were either reiterating or reinforcing the positions of moral entrepreneurs or claims-makers, who promulgated the idea that the media of the day had a negative impact on social behavior, promoting deviance or violence. In each decade, the presence of negative connotations was most common. However, in the 1950s, a similar proportion of texts presented both sides or even held a null or positive connotation. These texts seemed to wrestle with the limited amounts of empirical evidence, much of which appeared to be rooted in small samples or case studies. Vedder (1954) commented, "[Comics] specific influence is not clear-although dramatic cases are occasionally brought to the attention of the public" (p. 87). Vedder leaned toward a no-influence or neutral position, but then nodded to the moral entrepreneurs:

To be sure, illegal conduct ... is often undeservedly glamorized by the motion pictures, by radio and television, and by the comics. There can be no quarrel with those who decry this situation or with those who condemn the tabloid publicity that so often gives crime and delinquency a kind of prestige. But the causes of delinquency and the reasons for its persistence are many and complex. Mass media ... play their part. (p. 87)

In the 1990s, negative connotations were clearly the most frequent, followed by neutral connotations. Null or positive connotations were few, and no textbook presented both sides of the issue without commentary. One example of this negative stance is illustrated in Maguire and Radosh (1999), who asserted:

There is little debate about the nature of the relationship between media violence and subsequent societal violence. ... The relationship between media violence and societal violence is a subtle force that influences some more than others. ... The internalized understanding of violence as an appropriate response to discord, combined with daily examples of widespread societal violence and a ready supply of media examples for imitation, may instigate violence in undefinable ways. (p. 83-84) 
A more provocative version of this negative stance is represented by Bartol (1999). After questioning the position of a study purporting no causal link (p. 195), several studies were reviewed, primarily on television effects. The section concluded, "[A]fter over three thousand studies on the effects of violent media and aggression [about 15 were cited, alongside examples of mass shootings], the overwhelming conclusion is that violent television and movies do increase aggressive tendencies in both children and adults" (p. 197).

Like the 1990s, negative connotations in the 2000s predominated and no null or positive connotations appeared, but more texts presented both sides of the issue or took a neutral stance on the purported media-crime relationship. For example, in Siegel and Welsh's (2009) text, 2 pages were devoted to reviewing research on the level of violence in media, children's exposure, and the evidence demonstrating a media-crime effect, and included a color photo of a child playing a first-person shooter video game (p. 96). One-third of a page was devoted to alternative explanations for the "persuasive" evidence for the relationship between TV viewing and violence, offered by "critics" of the research (p. 98). The paragraph concluded, "Further research is needed to clarify this important issue" (p. 98). Similarly, Cassel and Bernstein's (2001) text devoted 5 pages to reviewing research generally supportive of the negative effects of media on violence, occasionally peppered with the points made by critics. On the issue of video games, the text pointed out:

Recent studies have found a positive correlation between playing violent video games and aggressive behavior and delinquency, particularly in males. It has been suggested that these games may be even more harmful than violence in television and movies because they are interactive, psychologically addictive, and require players to become more aggressive.... There is still much to learn about the nature and strength of correlations between violent crime and violence video games, however. (p. 121)

Texts like these affirmed some sort of media-crime relationship, while suggesting additional variables may matter and that additional research was needed.

As shown in Table 1, the most prominent patterns in the use of in-text or footnoted citations were within, rather than across, these decades. In the 1950s, texts presenting both sides cited older research, whereas those taking a negative position presented more current research. In the 1990s, texts taking neutral positions cited older research, and those taking a negative position cited more current research. By the 2000s, there was a change. Texts taking a negative stance incorporated older research, and those taking a neutral stance more often presenting recent research, with texts presenting both sides falling in the middle. Books in the 1990s and 2000s, even those that cited older research, did not appear to cite research old enough to build a discussion around the ebb and flow of panics about the effect of media on crime. Earlier media types would have been referenced in older works, and not accessing such work may also indicate generational forgetting. 
Table 1. Average difference between publication date and reference dates, by connotation, selected decades

\begin{tabular}{|c|c|c|}
\hline Year & Average difference (in years) & Connotation \\
\hline 1953 & 4.0 & Negative \\
\hline 1954 & 13.5 & Negative \\
\hline 1955 & 13.6 & Positive \\
\hline 1956 & 15.0 & Positive \\
\hline 1956 & 24.3 & Both sides \\
\hline 1957 & 17.7 & Both sides \\
\hline 1995 & 3.0 & Negative \\
\hline 1996 & 10.0 & Negative \\
\hline 1997 & 17.6 & Negative \\
\hline 1999 & 4.3 & Negative \\
\hline 1998 & 7.0 & Positive \\
\hline 1995 & 11.8 & Neutral \\
\hline 1995 & 23.5 & Neutral \\
\hline 1997 & 15.0 & Neutral \\
\hline 2000 & 24.3 & Negative \\
\hline 2002 & 9.3 & Negative \\
\hline 2003 & 8.0 & Negative \\
\hline 2008 & 4.0 & Negative \\
\hline 2009 & 8.5 & Negative \\
\hline
\end{tabular}




\begin{tabular}{|l|l|l|}
\hline 2009 & 20.0 & Negative \\
\hline 2009 & 21.9 & Negative \\
\hline 2000 & 11.0 & Both sides \\
\hline 2001 & 13.3 & Both sides \\
\hline 2006 & 9.8 & Both sides \\
\hline 2008 & 18.5 & Both sides \\
\hline 2000 & 2.0 & Neutral \\
\hline
\end{tabular}

Given that television and movies were the most frequently mentioned in the 1990s and 2000s, followed by emergent forms of media such as video games, textbooks may have been reframing earlier research to fit the current narrative regarding video games. For instance, in Siegel and Welsh's (2009) text, the section began with the subtitle Media and Violence in which half a page was devoted to computer and video games. This led into a longer section about television and violence, and the section concluded with a bulleted summary of the effects of media violence on adolescent behavior. Overall, the citation patterns hint at the selective use of the research literature to create a particular point of view; however, because a large minority of books did not employ in-text citations, firm conclusions on the use of published research to craft a text cannot be made.

\section{Conclusions and fut ure directions}

Public discussion and policy debates regarding the media-crime relationship tend to suffer from generational forgetting about the topic and the panics surrounding it; scholarly research can be similarly forgetful. Thus, where the criminological enterprise stands on these issues over time is not well-known, nor is the degree to which it is influenced by moral panics. The current study examined textbooks in order to shed light on the position of the criminological enterprise over time and explore how scholarly attention to the media-crime relationship may be subject to moral panics.

Nearly half the sample of textbooks addressed the media-crime relationship in some capacity. Results of the content analysis revealed interest in media effects reaching back to the turn of the twentieth century, a lull of interest in the Depression and World War II eras, and increased interest beginning in the 1950s, with a dip in the 1980s. Proportionally, the media-crime relationship received the most coverage in the 1950s, 1990s, and 2000s. Although television and movies were mediums of enduring attention in textbooks, these decades correspond to surges of public interest surrounding comic books 
and, later, video games and computers. Comics were cited through the 1970s and were essentially replaced by video games in the 1990s. Texts that covered the media-crime relationship seemed to be responding to-and frequently concurring with-public debates brought on by moral panics.

As violence became an increasing social problem, at least as reflected in official crime rates, so too did coverage of its purported relationship with media. The caveat is the 2000s, during which concerns about violence still dominated the textbooks but violent crimes had fallen precipitously in official rates. The increased media and public attention given to anomalous mass shooting events and other extreme crimes, which appeared to run counter to the declining rates, nonetheless fueled panic about video games and media violence (Kappler \& Potter, 2005; Muschert, 2007). Textbooks most frequently took a negative stance on the media-crime relationship, as opposed to a more neutral stance or balanced approach. Such an emphasis on violence and on the overall negative effects of media on behavior may be due in part to an increase in research on the effects of media on violence specifically, which was often undergirded by theories biased toward negative effects (Gunter, 2008). Moreover, given the pitfalls associated with potential publication bias toward studies that find the expected effects and against those that either find unconventional or no effects (Ferguson \& Heene, 2012), literature reporting negative effects may have appeared to form the bulk of information on which the textbooks could draw. However, given that some texts did present both sides of the issue or reported the overall effect of media on crime as neutral, research on which to base such content was available. If such information were available, and neither employed nor balanced against more negative information, then another explanation is needed.

The emphases taken in these texts, and in the literature more generally, may therefore be indicative of scholars' participation in the moral panic process (Ferguson, 2008) and issue attention cycle (Downs, 1972), at least during the peak decades. Scholars become part of the moral panic by producing research that supports the original fear, but failing to publish null findings or suppressing research critical of the feared phenomenon (Ferguson \& Kilburn, 2009). Textbooks become part of the overall statement of scholars on issues, and the results of this analysis suggest that textbooks, too, can suppress critical evidence or fail to discuss null findings in an evenhanded manner.

Furthermore, consistent with the idea that concern or panic cannot be maintained, the lack of attention in the 1980s may represent a lull in the panic cycle. The public had lost interest in media issues, at least as they related to behavioral outcomes, and scholars had to move on to other topics. ${ }^{9}$ By the 1990s, the media and the public (or at least certain moral entrepreneurs), in the context of increasing violent crime rates, refocused their attention on the media-crime relationship. Likewise, in the textbooks, while some of the concern about television and movies reoccurred, newer forms of media garnered attention, as did their purported negative impact on behavior. Such narratives can take advantage of the groundwork laid by previous panics while at the same time downplaying or 
failing to acknowledge them (Goode \& Ben-Yehuda, 1994). Very few texts analyzed for this study drew attention to the notion of moral panic surrounding these issues. Authors may apply their own standards when judging a phenomenon and are unlikely to be wholly objective in their interpretation of it (Garland, 2008). Ultimately, the decision to take a negative position in texts may reflect scholarly authors' participation, intentionally or not, in the panic process. As the second decade of the twentyfirst century unfolds, it remains to be seen whether textbooks will continue rehashing such arguments or whether they will become more reflective in their approaches, giving attention to the full range of available research and being mindful of the social forces that shape both research and pedagogy.

There were several limitations to the study. First, we were limited in our sample by those books readily available to us, some of which may not have been in wide circulation. The sample was also potentially limited by trends particular to the library (e.g., purchasing lows and highs, selection decisions). A more expansive sample that took into consideration sales and circulation patterns and expanded to other libraries may have yielded more diverse results. Relatedly, we were unable to account for the survival of some older texts over others, as well as the absence of books from certain periods. The relatively fewer texts available from the earliest decades may limit the validity of crossdecade comparisons. Although the sample of texts may impede the generalizability of the study, this study represented a unique attempt to discern the role of scholars in the moral panic process.

Second, because the coding effort took an ethnographic approach and involved one primary coder, it not amenable to the same sort of validation metrics advised by Maxfield and Babbie (1995). As a result, other coders may have had different insight into the process. Third, the analysis focused on media as a correlate of crime that fuels moral panics. However, other presumed correlates of crime also have moral implications, such as concerns about drug use and the decline of so-called family values (e.g., Bennett, Dilulio, \& Walters, 1996). Future research could expand to include an analysis of these issues and their relationship to moral panics about crime. Fourth, given the emphasis on textbooks, we did not consider the full realm of special topics books that focus exclusively on the media-crime relationship. Presumably, such topical books would be more likely to be penned and published as panics arise. An analysis of their perspectives would add to our understanding of the role of scholarly work in the moral panic process.

Finally, the analysis was not amenable to causal arguments and with out directly consulting with authors and editors of textbooks, it is impossible to know if they were mindful of their roles in the moral panic process (see Turner, et al., 2006). To address this issue, future research could use the textbooks' authors as the unit of analysis and consider factors such as discipline, theoretical orientation, or research activity. For example, such research could investigate other work published by the authors (e.g., empirical studies) to determine if the authors' other published work related to 
media and took a distinct perspective, particularly compared to authors who are not primarily engaged in research. $\underline{10}$

Certainly, it is important to avoid overstating the impact of textbooks. After all, more than half of the sample did not mention the media-crime relationship at all, and much of the coverage that did occur was in the most recent decades. Nevertheless, textbooks are one location in which the criminological enterprise chronicles its scholarly history and speaks to the public-at-large, making texts an important site for understanding how scholars interpret the media-crime relationship. To trace the history more fully and to understand its intersection with moral panics, a content analytic inquiry of the published literature that remains cognizant of social history, examines the full range of media types, and focuses not just on methods or results, but on how hypotheses are crafted and results are discussed is a necessary step forward. Scholars may think themselves above the fray, but this study reveals that they can play a role in it, whether intentionally or unintentionally. Unveiling the commonalities across history and recognizing scholars' roles in moral panics can assist us in avoiding the scapegoating Thrasher (1949) prophetically warned us against.

\section{References}

Altheide, D. L. (1987). Ethnographic content analysis. Qualitative Sociology, 10, 65-77.

Altheide, D. L. (1997). The news media, the problem frame, and the production of fear. Sociological Quarterly, 38, 647-668.

Altheide, D. L. (2009). Moral panic: From sociological concept to public discourse. Crime, Media, Culture, 5, 79-99.

American Psychological Association. (1985). Resolution on television violence. Retrieved June 13, 2014 from http://www.apa.org/about/policy/archive.aspx?item=12

American Psychological Association. (1994). Violence in Mass Media. Retrieved June 13, 2014 from http://www.apa.org/about/policy/media.aspx

American Psychological Association. (2005). Resolution on Violence in Video Games and Interactive Media. Retrieved June 13, 2014 from http://www.apa.org/about/policy/interactive-media.pdf

Anderson, C. (2013). Games, guns, and mass shootings in the U. S. The Bulletin of the International Society for Research on Aggression, 35, 15-19.

Bartol, C. R. (1999). Criminal behavior: A psychosocial approach, 5th ed. Upper Saddle River, NJ: Prentice Hall. 
Bennett, W. J., Dilulio, J. J., \& Walters, J. P. (1996). Body Count: Moral Poverty and how to Win America's War against Crime and Drugs. New York, NY: Simon \& Schuster.

Britto, S., \& Dabney, D. A. (2010). “Fair and Balanced?” Justice issues on political talk shows. American Journal of Criminal Justice, 35, 198-218.

Brown v. Entertainment Merchants Association, 132 S. Ct. 81 (U.S. 2011).

Brown, J. D., \& Bobkowski, P. S. (2011). Older and newer media: Patterns of use and effects on adolescents' health and well-being. Journal of Research on Adolescence, 21, 95-113.

Burns, R. G., \& Katovich, M. A. (2006). Melodramatic and consentient images in introductory criminal justice textbooks. Journal of Criminal Justice, 34, 101-114.

Carey, B. (2013). Shooting in the dark.

Cassel, E., \& Bernstein, D. A. (2001). Criminal Behavior. Needham Heights, MA: Allyn \& Bacon.

Cohen, R. D. (1997). The delinquents: Censorship and youth culture in recent U. S. history. history of Education Quarterly, 37, 251-270.

Cohen, S. (1972). Folk Devils and Moral Panics: The Creation of Mods and Rockers. London, England: MacGibbon and Kee.

Cohen, S. (2002). Folk Devils and Moral Panics: The Creation of Mods and Rockers, 3rd ed. London, England: Routledge.

Cooper, A., \& Smith, E. L. (2011.) Homicide trends in the United States, 19802010. u.S. Department of Justice, Office of Justice Programs, Bureau of Justice Statistics. Retrieved September 3, 2014 from http://www. bjs.gov/content/pub/pdf/htus8008.pdf

Coyne, S. M. (2007). Does media violence cause violent crime? European Journal on Criminal Policy and Research, 13, 205-211.

Critcher, C. (2008). Making waves: Historical aspects of public debates about children and mass media. Pp 91-104 in S. Livingstone and K. Drotner, eds, International handbook of Children, Media and Culture. London: Sage

Downs, A. (1972). Up and down with ecology: The issue attention cycle. Public interest, 28, 38-50.

Elliot, D. L., \& Woodward, A. (1990). Textbooks and Schooling in the united States. Chicago, IL: University of Chicago Press. 
esrb.com, (n.d.). ESRB history. Retrieved February 15, 2014 from

http://www.esrb.org/about/chronology.jsp

Faucher, C. (2008). Fear and loathing in the news: a qualitative analysis of Canadian print news coverage of youthful offending in the twentieth century. Journal of Youth Studies, 12, 439-456.

Felson, R. B. (1996). Mass media effects on violent behavior. Annual Review of Sociology, 22, 103-128.

Ferguson, C. J. (2008). The school shooting/violent video game link: Causal relationship or moral panic? Journal of Investigative Psychology and Offender Profiling, 5, 25-37.

Ferguson, C. J. (2010). Blazing angels or resident evil? Can violent video games be a force for good? Review of General Psychology, 14, 68-81.

Ferguson, C. J. (2013). Violent video games and the Supreme Court: Lessons for the scientific community in the wake of Brown v. Entertainment Merchants Association. American Psychologist, 68, 57.

Ferguson, C. J., \& Heene, M. (2012). A vast graveyard of undead theories: Publication bias and psychological science's aversion to the null. Perspectives on Psychological Sciences, 7, 555-561.

Ferguson, C. J., \& Ivory, J. D. (2012). A futile game: On the prevalence and causes of misguided speculation about the role of violent video games in mass school shootings. Studies in Media and Communications, 7, 47-67.

Ferguson. C. J., \& Kilburn, J. (2009). The public health risks of media violence: A meta-analytic review. Journal of Pediatrics 154. 759-763.

filmratings.com (n.d.). Why: History of ratings. Retrieved September 30, 2013 from http://www.filmratings.com/why.html

Fox, J. A., \& DeLateur, M. J. (2014). Mass shootings in America: moving beyond Newtown. homicide Studies, 18, 125-145.

Garland, D. (2008). On the concept of moral panic. Crime, Media, Culture, 4, 9-30.

Gauntlett, D. (1995). Moving experiences: understanding television's influences and effects. Luton, UK: John Libbey.

Goode, E., \& Ben-Yehuda, N. (1994). Moral panics: Culture, politics, and social construction. Annual Review of Sociology, 20, 149-171.

Grimes, T., \& Bergen, L. (2008). The epistemological argument against a causal relationship between media violence and sociopathic behavior among psychologically well viewers. American Behavioral 
Scientist, 151, 1137-1154.

Gunter, B. (2008). Media violence: Is there a case for causality? American Behavioral Scientist, 51, 10611122.

Hajdu, D. (2008). The Ten-Cent Plague: The Great Comic-Book Scare and how it Changed America. New York, NY: Farrar, Straus and Giroux.

Heyward, T. (1885). Burlesque: Its uses and abuses. Tinsley's Magazine (November), p. 477.

Huesmann, L. R. (2007). The impact of electronic media violence: Scientific theory and research. Journal of Adolescent Health, 41, S6-S13.

Huffman, J., \& Overton, A. (2013). Missing the mark: The neglect of stalking and cyberstalking in introductory criminology textbooks. Journal of Criminal Justice Education, 24(2), 200-217.

Ingram, C. (2013). Now, here's something to get upset about. Tampa Tribune, September 28, 2013.

Jensen, G. F. (2001). The invention of television as a cause of homicide: The reification of a spurious relationship. homicide Studies, 5, 114-130.

Joseph Burstyn, Inc. v. Wilson, 343 U.S. 495, 72 S. Ct. 777, 96 L. Ed. 1098(1952).

Kappeler, Victor E. and Gary W. Potter. 2005. The Mythology of Crime and Criminal Justice. 4th ed. Long Grove, IL: Waveland Press.

Keith, B., \& Ender, M. G. (2004). The sociological core: Conceptual patterns and idiosyncrasies in the structure and content of introductory sociology textbooks, 1940-2000. Teaching Sociology, 32, 19-36.

MacDonald, A. (1892). Criminology. New York, NY: Funk \& Wagnalls. Maguire, B., \& Radosh, P. F. (1999). Introduction to Criminology. Belmont, CA: Wadsworth.

Maxfield, M.g., \& Babbie, e. (1995). Research methods for criminal justice and criminology. Belmont, CA: Wadsworth.

Media Violence Commission. (2012). Report of the Media Violence Commission. Aggressive Behavior, 38, 335-341.

Miller, M. K. (2009). Content analysis of the 18 -year evolution of violence in video game magazines. Journal of Criminal Justice and Popular Culture, 16, 81-102.

Mills, C. W. (1954). Nothing to laugh at. New York Times (April 25), p. BR20. 
Muschert, G. W. (2007). The Columbine victims and the myth of the juvenile superpredator. Youth Violence and Juvenile Justice, 5, 351-366.

Muzzatti, S. L. (2006). Cultural criminology: A decade and counting of criminological chaos. In W. S. DeKeserdy \& B. Perry (eds.), Advancing critical criminology: Theory and application (pp. 63-82). Lanham, MD: Lexington.

Parmelee, M. (1918). Criminology. New York: The Macmillan Company.

Rhineberger, G. M. (2006). Research methods and research ethics coverage in criminal justice and criminology textbooks. Journal of Criminal Justice Education, 17, 279-296.

Sacco, V. (1995). Media constructions of crime. Annals of the American Academy of Political and Social Sciences, 539,141-154.

Savage, J. (2004). Does viewing violent media really cause criminal violence? A methodological review. Aggression and Violent Behavior, 10, 99-128.

Schildkraut, J., \& Muschert, G. W. (2014). Media salience and the framing of mass murder in schools: A comparison of the Columbine and Sandy Hook massacres. homicide Studies, 18, 23-43.

Sciarabba, A. L., \& Eterno, J. A. (2008). Analyzing domestic abuse coverage in introductory criminal justice and criminology textbooks. Journal of Criminal Justice and Popular Culture, 15, 217-237.

Shih, T. J., Wijaya, R., \& Brossard, D. (2008). Media coverage of public health epidemics: Linking framing and issue attention cycle toward an integrated theory of print news coverage of epidemics. Mass Communication \& Society, 11, 141-160.

Shipley, W., \& Cavender, G. (2001). "Murder and mayhem at the movies." Journal of Criminal Justice and Popular Culture, 9, 1-14.

Siegel, L. J., \& Welsh, B. C. (2009). Juvenile Delinquency: Theory, Practice, and Law, 10thed. Belmont, CA: Wadsworth.

Springhall, J. (1998). Youth, Popular Culture and Moral Panics: Penny Gaffs to Gangsta-Rap, 1830-1996. New York, NY: St. Martin’s Press.

Strasburger, V. C., Donnerstein, E., \& Bushman, B. J. (2014). Why is it so hard to believe that media influence children and adolescents? Pediatrics, 133, 571-573.

Sutherland, E. (1947). Principles of Criminology, 4th ed. Philadelphia, PA: Lippincott. 
Thrasher, F. (1949). The comics and delinquency: Cause or scapegoat. Journal of Education Sociology, 23, 195-205.

Turner, K. B., Giacopassi, D., \& Vandiver, M. (2006). Ignoring the past: Coverage of slavery and slave patrols in criminal justice texts. Journal of Criminal Justice Education, 17, 181-195.

tvguidelines.org (n.d.). Resources. Retrieved February 15, 2014 from

http://tvguidelines.org/resources.htm

tvhistory.tv (n.d.). Televisions facts and statistics, 1939-2000. Retrieved March 1, 2014 from

http://www.tvhistory.tv/facts-stats.htm

United States Senate. (1954). Juvenile delinquency (comic books): Hearings before the Subcomittee to Investigate Juvenile Delinquency, United States Senate, Eighty-third Congress, second session, pursuant to S. 190, April 21, 22, and June 4, 1954.

United States Senate. (1985). Record labeling: Hearing before the Committee on Commerce, Science, and Transportation, United States Senate, Ninety-ninth Congress, first session, on contents of music and the lyrics of records, September 19, 1985.

van der Hoven, A. (2001). A critique on individual-oriented crime explanation in general textbooks on criminology and a proposed integrated model. Acta Criminologica, 14, 86-95.

Vedder, C. B. (1954). The Juvenile Offender: Perspective and Readings. New York, NY: Random House.

Wells, E. (2009). Uses of meta-analysis in criminal justice research: A quantitative review. Justice Quarterly, 26, 268-294.

Wertham, F. (1954). Seduction of the Innocent. New York, NY: Rinehart.

Withrow, B. L., Weible, K., \& Bonnett, J. (2004). Aren't they all the same? A comparative analysis of introductory criminal justice textbooks. Journal of Criminal Justice Education, 15, 1-18.

Wright, R. A. (2000). Left out? The coverage of critical perspectives in introductory criminology textbooks, 1990-1999. Critical Criminology, 9, 101-122.

\section{Contributors}

Lisa A. Kort-Butler is an Associate Professor of Sociology at the University of Nebraska-Lincoln. Her research focuses on adolescent and young adult well-being, including law violation and mental health. She is interested in the role of social psychological factors in the social processes that influence wellbeing. In addition, she studies media representations of crime and justice as they relate to attitudes and perceptions about the justice system. 
Michael Killingsworth received his Bachelor of Arts in Sociology, Psychology, and Political Science at the University of Nebraska-Lincoln.

\section{Footnotes}

1. The U.S. Supreme Court's majority opinion in Brown v. Entertainment Merchants Association, written by Justice Scalia, acknowledged the historical controversies over violence in media formats, including fairy tales, literature, dime novels, movies, radio, comic books, television, and music. $\leftrightarrows$

2. Research has dispelled the purported causal relationship between video game consumption and mass shootings (Fox \& DeLateur, 2014).

3. "Primary authors" refers to either sole or first authors of the texts. $\boxminus$

4. Dime novels were later collapsed into the books category. $\subseteq$

5. Because there were few cases in the individual categories, these two categories were collapsed. These categories run counter to the larger narrative of moral panics about media. $\triangleq$

6. Despite the consistent appearance of newspapers, their purported role in the media-crime relationship changed over time. While earlier references were concerned with the potential for copycat crimes, later references were more concerned with sensationalism, desensitization, and/or fear cultivation. $\subseteq$

7. Radio also represents a potential interpretive shift. In its early incarnations, radio had a good deal of programming, as well as music, but did not become subject to panic, in part because radio did not involve visual content (Critcher, 2008). Later, concerns about radio largely centered on the nature of the music available, and overlapped with concerns about music videos by the 1980 s. However, because texts did not make this clear distinction, we kept radio and music as separate categories. $€$

8. Numbers do not total $100 \%$ because a few texts were coded as representing more than one position, if, for example, media effects were covered in two different sections of a text.

9. The panic about music that occurred in the mid-1980s was both behavioral and attitudinal in nature. Music, as the testimony before Congress suggests (United States Senate, 1985), was thought to lead to poor mental health (e.g., suicide) and antisocial or immoral attitudes, but not necessarily crime. $\bullet$

10. An anonymous reviewer provided this suggestion. $€$ 